\section{The Stakeholder Approach to the construction of Performance Measures: some implications}

\author{
John C Crawford
}

\author{
The Author \\ Dr John C Crawford is Library Research Officer, \\ Glasgow Caledonian University
}

\begin{abstract}
A large questionnaire survey in 1995-96 covered ten stakeholder groups in fifteen UK higher education libraries to examine their views on 91 library performance measures. Those considered most important are discussed and the entire set is listed.
\end{abstract}

\begin{abstract}
Library management issues seemed much less important to users and to academics than to library staff. A hierarchical 'looking upwards' to groups above was noted.
\end{abstract}

Results supported the findings of earlier Stakeholder research overseas. It is suggested these results require conventional performance measures to be reviewed and extended. In particular The Effective Academic Library requires a broader perspective. These findings in the library world have subsequently been overtaken by a broad political 'Stakeholderism'.

\section{The Occasion}

'The Stakeholder Approach to the Construction of Performance Measures' was a BLRIC funded research project which began in July 1995 and concluded in November 1996. A report was made to the British Library Research and Development Department (British Library Research and Innovation Report 3I). Copies are available from, John C Crawford, Glasgow Caledonian University Library, Cowcaddens Road, Glasgow, G4 OBA. It is hoped that a research level article will appear later.

\section{Aims and objectives}

The aim of the research project was to design a set of user chosen performance measures, using the stakeholder method, which can be used in British academic libraries to improve customer service

The detailed objectives were:

1. To identify the following:

- a set of user (stakeholder) chosen performance measures, using the questionnaire method

- a small number of generally applicable "parsimonious" measures

- an appropriate number of meaningful stakeholder groups

- performance measures appropriate to particular stakeholder groups

2. To design semi-standardised questionnaires for:

- general use

- specific categories of users

3. To allow academic library managers to concentrate their attention on an independently validated set of measures.

A questionnaire consisting of 91 performance measures, each of which had to be graded on a scale of 1 to 7 , was distributed to 15 participating British university libraries.

\section{The Survey}

The list of stakeholders, decided upon in conjunction with the 15 participating libraries was:

1. Part-time undergraduate

2. Full-time undergraduate

3. Part-time postgraduate (taught)

4. Full-time postgraduate (taught)

5. Postgradate (research)

6. Research staff

7. Academic staff (teaching) 
8. Library staff (other than senior staff)

9. Senior library staff

10. Members of university senior management team

Sample Design and Sample Sizes It was decided to identify samples from small populations using a census, and for large populations using Krejcie and Morgan's table ${ }^{(1)}$ which gives suggested sample sizes for different population sizes. These samples were then doubled to allow for non-returns. Any further increase in sample size was impractical from the point of view of the participating institutions, since they were limited in the number of questionnaires they could handle. Most completed questionnaires were returned by the end of February 1996 and all were in by the end of April. They were distributed by internal mail or through lecturers and returned through a combination of internal mail and collection boxes. Several universities used the Royal Mail to contact students and they were supplied with pre-paid envelopes to encourage returns. In the end 33,797 questionnaires were distributed of which 6724 (20\%) were returned. Of these, $4193(62 \%)$ of the returns were fully completed and could be used to calculate the overall rankings.

\section{Analysis and Conclusions}

A particular value of the project was the inclusion of a large number of respondents, thus allowing identification of the characteristics of stakeholders and of the influence these have on different groups' requirements for library services. Each group was large enough to allow some consensus on different concerns to be reached, so that the user-oriented approach to performance measurement was supported. When considering individual stakeholder groups, it became clear that for many users there is still a "them and us" attitude in place, with library staff and university management on one side and users on the other. There is a tendency for each group to look upwards towards the next one, so that, for example, management issues become more important to researchers and to senior library staff.

Ranked outputs of performance issues were produced, both by all stakeholder groups in all institutions (Figure 1) and by individual stakeholder groups. Comparisons were made between service provider stakeholder groups and user stakeholder groups and also between pre and post 1992 universities. Of the 91 issues included in the questionnaire, 18 were rated as "very important" by at least $40 \%$ of the combined stakeholders and could be regarded as the key performance issues:

2 Helpfulness, courtesy of staff

4 Availability of enquiry desk staff when needed

5 Expertise of enquiry desk staff

18 Provision made for disabled users

24 Amount of regular maintenance of equipment

26 Adequacy of seat numbers

31 Match of open hours to user needs

42 Provision of multiple copies of items in high use

43 Speed and accuracy of re-shelving of materials

44 Availability of sought material on the shelf

56 Proportion of materials listed on computer catalogue

57 Availability of library catalogues throughout the library

58 Access to library catalogues / CD-ROMs / Internal databases via networks throughout the campus

65 Overall user satisfaction

70 Competence of library management

78 Total amount of library budget

79 Total amount of library budget as proportion of university expenditure

80 Flexibility of library budget to respond to new subject areas 


\section{Figure I: Rankings: Combined Responses}

Indicator

q42. Multiple copies provided

q65. User satisfaction

q02. Staff helpfulness

q18. Provisions for disable users

q56 Proportion of materials catalogued

q04. Enquiry staff available

q70. Competence of library management

q78. Total library budget

q44. Availability of materials on shelf

q31. Opening hours

q23. Cost of photocopying

q24. Regular equipment maintenance

q15. Quietness

q58. Catalogue networked within campus

q43. Re-shelving

q22. Photocopier numbers

$\mathrm{q} 91$. Extent to which services are free

q80. Budget flexibility

q57. Catalogue availability

q79. Budget as $\%$ of university budget

q69. Stock security

q05. Enquiry staff expertise

q26. Adequate seating

q34. Range of material types

q67. Currency of materials

qll. Amount of user education

q25. Seats : FTE student

q36. Publicity for services available

q81. Materials as \% of library budget

q62. \% enquiries answered

q51. Proportion of wanted items obtained

q35. Range of services

q38. Collection adequacy

q49. Speed of ILL

q59. Ease of use of OPACs

q13. Collection arrangement

q20. Remote database access

q63. Queues

q|4. Signing

q33. Total items held by library

q82. Budget allocation amongst subjects

q54. Acquisition speed

q48. Short-loan reservations available

q90. Cost efficiency of library

q89. Cost effectiveness of library

q37. Reciprocal access to libraries

q74. Library goals achieved

q03. Subject specialists available

q50. Recall speed of reserved items

q19. Computers provided for general use 50

\author{
Rank \%frequency Indicator \\ of 'very \\ important'
}

$60.79 \%$

$60.15 \%$

$58.55 \%$

$55.95 \%$

$54.38 \%$

$52.25 \%$

$51.87 \%$

$51.63 \%$

$51.56 \%$

$50.78 \%$

$48.39 \%$

$47.58 \%$

$46.51 \%$

$14 \quad 46.48 \%$

$15 \quad 46.46 \%$

$16 \quad 46.12 \%$

$17 \quad 45.72 \%$

$18 \quad 44.34 \%$

$19 \quad 44.05 \%$

$20 \quad 43.95 \%$

$21 \quad 43.86 \%$

$22 \quad 43.45 \%$

$23 \quad 41.19 \%$

$24 \quad 39.33 \%$

$25 \quad 39.18 \%$

$26 \quad 38.85 \%$

$27 \quad 38.66 \%$

$28 \quad 38.42 \%$

$29 \quad 38.33 \%$

$30 \quad 38.25 \%$

3। $37.99 \%$

$32 \quad .37 .94 \%$

$33 \quad 36.63 \%$

$34 \quad 36.47 \%$

$35 \quad 36.42 \%$

$36 \quad 36.20 \%$

$37 \quad 35.85 \%$

$38 \quad 34.94 \%$

$39 \quad 34.15 \%$

$40 \quad 33.99 \%$

4I $33.94 \%$

$42 \quad 33.79 \%$

$43 \quad 33.32 \%$

$44 \quad 33.20 \%$

$45 \quad 32.22 \%$

$46 \quad 32.03 \%$

$47 \quad 31.96 \&$

$48 \quad 31.84 \%$

$49 \quad 31.46 \&$

$30.93 \%$ q46. Flexibility of loan periods

$q / 2$. Suitability of library building

q32. Institution goals match user needs

q66. Time taken for journal binding

q61. CD-Rom serials indexes available

q39. All material available for browsing

q87. Expenditure per FTE student

q45. Borrowing entitlement

q76. Communication with user groups

q08. Level of staff training

q09. Workload levels

q55. New stock notification

q01. Staff per FTE student

q47. Proportion of stock in short-loan

Rank \%frequency of 'very

important'

$51 \quad 29.81 \%$

$52 \quad 29.12 \%$

$53 \quad 28.74 \%$

$54 \quad 28.33 \%$

$55 \quad 27.74 \%$

$56 \quad 27.55 \%$

$57 \quad 26.47 \%$

$58 \quad 26.26 \%$

$59 \quad 24.99 \%$

$60 \quad 24.23 \%$

$61 \quad 24.04 \%$

$62 \quad 23.99 \%$

$63 \quad 23.47 \%$

$64 \quad 23.13 \%$

q60. Printed serials indexes available $\quad 65 \quad 22.44 \%$

q52. User recommendation mechanisms $66 \quad 22.39 \%$

q88. Expenditure per FTE researcher $\quad 67 \quad 22.25 \%$

q64. Sanctions policy $\quad 68 \quad 21.04 \%$

q75. Openness of management $\quad 69 \quad 20.70 \%$ procedures

q17. Provision of carrels $\quad 70 \quad 20.46 \%$

q16. Provision of group study rooms $71 \quad 20.15 \%$

q53. Feedback to users $\quad 72 \quad 19.84 \%$

q40. Usage of reference collection $\quad 73 \quad 19.51 \%$

q68. State of repair of stock $\quad 74 \quad 19.29 \%$

q06. Counter staff expertise $\quad 75 \quad 19.15 \%$

q77. User involvement in decision- $\quad 76 \quad 18.65 \%$ making

q29. \% potential users using the library $\quad 77 \quad 18.48 \%$

q27. Library proximity to teaching areas $78 \quad 18.20 \%$

q84. \% material budget spent on research $79 \quad 17.17 \%$

q83. Books : serial budget $\quad 80 \quad 16.60 \%$

q73. Use of planning procedures $\quad 81.1 \quad 16.17 \%$

q85. Staff budget as \% of library budget $81.2 \quad 16.17 \%$

q21. Provision of audio-visual $\quad 82 \quad 14.81 \%$ equipment

q07. Proportion of qualified staff $\quad 83 \quad 13.31 \%$

q86. Cost per item

q72. Stock development policies

$84 \quad 12.47 \%$

q30. Vacation : term time usage ratio $86 \quad 10.80 \%$

q28. Refreshments proximity to library $87 \quad 10.59 \%$

q10. Staff involvement in organisation $88 \quad 10.28 \%$

q41. \% collection borrowed $\quad 89 \quad 10.02 \%$

q71. Management policies $90 \quad 6.58 \%$ 
The above preferences show that there is more interest in direct user services and the ability of library management to deliver them than in involvement and feedback issues. If the university is interested in involving users in decision making, rather than just making them aware of what has been decided, it would need to look at mechanisms which would encourage them to be involved in future planning. This point may be allied to the apparently low interest in internal library management and also to the low value placed on the mission statement approach. Both Number and quality of written management policies and Use of planning procedures (long and short term) received low ratings. Users are more motivated by the provision of hard information about services than by the possibility of involvement in strategic planning, a fact which has particular implications for the planning of user education and the identification of relevant publicity material relating to library services.

It was not possible to identify an objectively validated method of recognising the most important and least important issues. The figures of $40 \%$ of respondents' highly placed preferences and $25 \%$ for low preferences which were used as cut-off points were reached by studying the tables of rankings and making a subjective judgement.

Planning of library accommodation could be influenced by the low rating given to Provision of group study rooms, Provision of carrels and Proximity of refreshment service during library open hours as well, of course, by university-wide decisions about the provision of computers for general use. These issues are usually the outcome of the teaching methods favoured by the university, and regular evaluation of this requirement would need to be undertaken.

Because of its generally low ranking, there may be a case for reducing audio-visual provision. This would have implications for purchase and maintenance of equipment and for appropriate staffing.

Since all student groups rate the availability of multiple copies very highly, there could be implications for the supply of electronic textbooks. On the other hand, some user groups, particularly undergraduates and postgraduates on taught courses, do not appear to be interested in
IT applications, and the idea of the Virtual Library may not be attractive to them. This attitude may require to be addressed if full advantage is to be taken of developments in this field. However, it is evident that attitudes to IT issues vary from one university to another and from one stakeholder group to another and each institution would be advised to study this issue in more depth.

The provision of multiple copies, together with IT issues and cost issues constitute possible areas of conflict, not only between providers and users, but also amongst identifiable groups.

Consideration would also have to be given to the rating for Extent to which services are free, which was highly rated by users but lower by service providers, and to the fairly low rating for Equitable and effective sanctions policy. The possibility of charging for some services, such as photocopying, Microform copying and interlibrary loans would have to be considered in the light of users' concern for the availability of free services.

There is a need to invest more time and effort in user education and information services for parttime undergraduates, whose access to the library is limited by time constraints and, often, poor information-seeking skills.

Some contradictions relating to staffing arose in the analysis of the questionnaires. There was a high ranking for Availability of enquiry desk staff when needed but a low rating for Counter staff expertise, Levels of staff training and Proportion of qualified staff, and a relatively low ranking for Subject specialists available to provide assistance to users. It is questionable whether participants understood the difference between enquiry staff and subject specialists, and they were not necessarily knowledgeable about the skills required by counter staff, the depth of knowledge acquired by subject specialists or the need for staff training. It would seem necessary to give more information to users about the skills, expertise and training of library staff, so that they could make more appropriate judgements about the level of assistance they require.

The comparison with current performance measurement documents demonstrates that in some instances, notably the recommendations of the Follett Report ${ }^{(2)}$, the stakeholder approach to 
rating attached to Extent to which services are free. These issues can only be resolved by further, qualitative based, evaluation.

Different user stakeholder groups have widely differing needs and there is scope for conflict between groups, especially on issues of access to basic textbooks. The research casts doubt on the viability of on demand publishing exercises for, although all student groups rate the availability of multiple textbooks very highly, they are not very interested in IT applications and furthermore are extremely concerned about the costs attaching to the reproduction of core reading materials. This may explain why attempts to replace short loan collections with electronic, on demand access have had limited success.

Stakeholderism The project aimed to identify empirically viable stakeholder groups and successfully accomplished this. Recently 'stakeholderism' has emerged as a popular ideology and has even been espoused by the prime minister who believes that competitive success in business comes from a stakeholder approach and that companies which treat their workers as partners are the ones which succeed. ${ }^{(8)}$ Several large companies have taken up the idea and, as yet, it exists mainly as a macroeconomic idea. Will Hutton, the editor of The Observer in The state to come, an overt attempt to influence the new Labour government ${ }^{(9)}$, links 'stakeholderism' with the following

- the promotion of an investment culture

- the promotion of intermediate institutions between government and the electorate

- a bottom up rather than top down approach to government and administration

- the promotion of equality

- the sharing of responsibility

To what extent this philosophy is applicable to the public sector in general and librarianship in particular requires further debate but there are germs of the idea in The Effective Academic Library (EAL) 'P1 Integration', 'P2 User satisfaction' and especially 'P2.35' which states

"Library managers should ensure that user constituencies are regularly invited to appraise the effectiveness of the library operations and services"
The key question is: What mechanisms in university libraries are likely to facilitate stakeholderism? Qualitative mechanisms can be resource intensive and likely to lose credibility if they do not produce timeous, useful results. However stakeholder mechanisms are likely to be more successful and valued if they are seen to promote the integration of the library into the university community as proposed by The Effective Academic Library (EAL). Another potential stumbling block is the possible hostility between senior library managers who do not seem to identify with user stakeholder groups on some key issues. However Davies and Kirkpatrick have argued that, as a result of the imposition of performance indicators, academic librarians have lost much of their workplace autonomy ${ }^{(10)}$. While their case is open to argument it raises the question of whether new means of accountability can offer a useful way forward.

Changing the evaluation climate Throughout the $90 \mathrm{~s}$ academic libraries have lived in a climate of evaluation centering round such methods as teaching quality assessment, research assessment exercises and departmental reviews. The evaluation culture which permeates higher education, although praiseworthy in principle, is in practice, labour intensive, time consuming, cumbersome and is prone not to produce decision making information timeously. A more flexible ad hoc strategy which identifies problems quickly and facilitates action seems a possible alternative. The Stakeholder project, by identifying key performance issues has pointed the way to a strategy in which data could be collected directly from stakeholders using a mix of quantitative and qualitative methods. Qualitative evaluation could be based on pre-existing quantitative data and research could be undertaken to identify the most fruitful qualitative methodologies, an approach which would extend The Effective Academic Library (EAL) document.

\section{References}

1. Krejcie, R.V and Morgan, D W. Determining sample size for research activity. Educational and psychological measurement. 30, 1970.pp. 607-610. 
2. Joint Funding Councils' Library Review Group: Report. Bristol: Higher Education Funding Council for England, December 1993 ('Follett Report').

3. Joint Funding Councils The Effective Acadenic Library: a framework for evaluating the performance of UK academic libraries. Bristol: Higher Education Funding Council for England, 1995.

4. ISO 11620. Information and documentation library performance indicators, 1998. [forthcoming]

5. Poll, R and te Boekhorst, P. Measuring quality: international guidelines for performance measurement in academic libraries. Munich: K G Saur, 1996. (IFLA publications 76)

6. Pickering, Helen, Crawford, John C, McLelland, Dorothy. The stakeholder approach to the construction of performance measures: a report to the British Library Research and Development Department. Glasgow: Glasgow Caledonian University, 1996. (British Library Research and Innovation Report 31).Copies of the report are available from, John C Crawford, Glasgow Caledonian University Library, Cowcaddens Road, Glasgow, G4 OBA. It is hoped that a research level article will appear later.

7. Cullen, R.J. and Calvert, P.J. Stakeholder perceptions of university library effectiveness. Journal of academic librarianship. Nov., 1995. pp 438-448.

8. Blair, Tony. 'The Stakeholder economy'. Speech to a public meeting at Assembly Rooms, Derby, 18.1.96. (Press release available from the Labour Party)

9. Hutton, Will. The state to come. London: Vintage, 1997.

10. Davies, Annette and Kirkpatrick, Ian. Performance indicators, bureaucratic control and the decline of professional autonomy: the case of academic librarians. In Kirkpatrick, Ian and Martinez Lucio, Miguel.eds. The politics of quality in the public sector: the management of change. London: Routledge, 1995. pp.84-107. 